\title{
Integration as a Key Strategy for Achieving Person- and People- Centered Care
}

\author{
Juan E. Mezzich MD MA MSc PhD and James Appleyard MA MD FRCPb \\ a Professor of Psychiatry, Icahn School of Medicine at Mount Sinai, New York; Secretary General, International College of \\ Person Centered Medicine, New York, United States of America. \\ b President of the International College of Person Centered Medicine; Vice-President of the International Association of \\ Medical Colleges; Former President of the World Medical Association, London, United Kingdom
}

\section{Keywords}

Person Centered Medicine, Person- and people-centered care, Integration, Integrated Care, Geneva Conferences, Goals and strategies, Fragmentation, Compartmentalization, Communication, Relationships.

\section{Correspondence Address}

Juan E. Mezzich, M.D., Ph.D., Professor of Psychiatry, Icahn School of Medicine at Mount Sinai, Fifth Avenue and 100th Street, Box 1093, New York, New York 10029, USA. E-mail: juanmezzich@aol.com

\section{Fundamental Purpose and Strategies in Person Centered Medicine}

The fundamental purpose of Person Centered Medicine (PCM) (and by extension of Person- and People-centered Care), is to promote the health and well-being of the totality of the person [1]. Here the person is the central concept [2], which should be understood in a contextualized manner. This is illustrated by Ortega y Gasset aphorism "I am I and my circumstance, and if do not care for it I do not care for myself" [3].

In the discussion of what is central and what is instrumental in PCM, the eminent Indian scholar Shridhar Sharma (personal communication, 2012) has cogently stated that in medicine science is essential and humanism is the essence of medicine. It can be argued that the instrumental role of science could be shared by other important concepts and activities, such as integration, with similar functional roles vis-a-vis person- and peoplecentered care. Thus, when examining the World Health Organization's emerging six-year work plan seeking as a major objective person-centered integrated care [4], one could understand people-centered as the soul or essence and integration as a key methodology or strategy.

\section{The Aspects and Levels of Integration}

A recent study conducted by the International College of Person Centered Medicine on the systematic conceptualization of person centered medicine and personand people-centered care [5] identified a relationship matrix among eight key concepts underlying the field. This relationship matrix involves communication and integration at all levels. In order to energize and sustain the integration at its various levels, there must be common values, shared vision of the future, and substantial commitment among all key stakeholders in all sectors of society to nurture the development of well-being for all. This keenly involves ethics promotion, as discussed in recent conferences with the involvement of the World Health Organization, the World Medical Association and the ICPCM $[6,7]$

Integration can play multiple functional roles at various important levels in the health field. The most crucial ones appear to be the following:

- $\quad$ First are the relations among the people seeking and delivering care. Particularly critical and emblematic here is the relationship or encounter between the doctor or clinician and the patient. Also important is the relationship between other health professionals and the patient.

- Within the social network of each person one can identify the significant relations between the patient and members of his/her family, community, and society at large.

- Health care must also be coordinated over the trajectory of each person's life. This recognizes the dynamics of human development and the networks that are at play at each of its phases.

- $\quad$ The coordination required among primary care-givers and specialists is receiving increasing attention. A number of experimental models are being examined that consider the protagonists and the functional relations among care-givers.

- A horizontal integration of health care delivery is that required across multiple sectors of society. Among these are education, social care, employment, housing, 
transportation, justice, finance, ecological management, and general government.

\section{The ICPCM and Integration: The 2014 Geneva Declaration}

Building on previous knowledge development efforts [812], the International College of Person Centered Medicine organized the preparation of the 2014 Geneva Declaration on Person- and People Integrated Care for All. The selection of this topic as the main theme of the $7^{\text {th }}$ Geneva Conference and the focus of the 2014 Geneva Declaration was in line with the World Health Organization's current six-year work plan addressing universal access to peoplecentered integrated care [4]. The 2014 Geneva Declaration is published in full in this issue of the Journal [13]. It pointedly addresses global health equity, argues that health care for all must be integrated to be effective, and discusses the various levels of integration crucial in the health care field. It then calls for collaborative action in the following ten areas: awareness, alliance building, intersectoral and interdisciplinary collaboration, health promotion, research, quality assurance, education and training, knowledge exchange, policy, and funding.

An article by Cloninger et al [14] follows the presentation of the 2014 Geneva Declaration. It discusses cogently the Declaration's foundations and highlights the urgent need for action on health inequities. It substantially reviews the pertinent literature and critically examines examples of universal healthcare systems in Chile, Spain, and Cuba.

\section{Introducing other published articles}

Braaf et al [15] studied pharmacist-patient medication communication during admission and discharge in specialty hospital settings at the University of Melbourne in Australia and reviewed implications for person centered healthcare. This particular type of healthcare communication, not frequently investigated, constitutes an intriguing aspect of integrated care. Their approach to communication complexity involved examining the sociocultural and environmental influences on communication processes, the characteristics of actual communication encounters, and their outcomes.

Gunnarsson et al [16] review hip-fracture patients' experience of involvement in their own care at Upsala University in Sweden. Aspects examined included pain, dependence on the nurses, feeling valued, organization of care, sharing a room with fellow patients, and encouraging interactions with nurses. Some of these aspects are related to integration of care. The authors posited that understanding patients' experience is essential in order to both meet patient expectations and ensure delivery of highquality nursing care.

Nes et al [17] through a cooperative study at Scandinavian universities examined the fidelity of web- based acceptance and commitment interventions for women with chronic widespread pain. These innovative and increasingly employed relational therapies involve communication and motivation strategies. They were applied through the internet, e-diaries, and mobile devices and appear relevant to address prevalent chronic problems. Their feedback analysis used both inductive and deductive approaches.

Basara et al [18] present and discuss a person-centered approach to pulmonary rehabilitation at Zagreb University in Croatia. They highlight the holistic scope of the approach, its emphasis on collaborative teams (integrative ion this sense), and focus on the person's specific needs. It includes a study on the impact of the person-centered approach to pulmonary rehabilitation on patients' quality of life, anxiety, depression and stress levels.

Walsh [19] a philosopher and practicing doctor from New Zealand presents a critical analysis of EvidenceBased Medicine by engaging the lens of the neo-pragmatist Richard Rorty. Walsh, who has challenged before Evidence Based Medicine from a number of philosophical perspectives such as Popperian [20], in the present paper focuses on how to deal with experiences such as suffering within the vicissitudes of practical care.

\section{Concluding Remarks}

The Journal's present issue highlights the strategic importance of integration for achieving person- and people-centered care. Integration is a key methodology in medicine and health care to fulfill its soul. In addition to the 2014 Geneva Declaration and its accompanying academic paper, a number of articles address various aspects of integration in either conceptual or empirical data-based manners or both. The issue at its end presents information about recent and upcoming events of relevance to person centered medicine.

\section{Acknowledgements and Disclosures}

The authors report no financial support nor conflicts of interest concerning this paper.

\section{References}

[1]. Mezzich JE, Snaedal J, van Weel C, Heath I (2009): The International Network for Person-centered Medicine: Background and First Steps. World Medical Journal 55: 104-107.

[2]. Cassell E (2010): The person in medicine. International Journal of Integrated Care. Vol 10. Supplement: 50-51.

[3]. Ortega y Gasset J (1914). Meditaciones del Quijote. In: Obras Completas de José Ortega y Gasset. Madrid: Editorial Santillana, 2004, Vol 1, pp:745-825.

[4]. World Health Organization (2013): Program of Work 20142019 of the WHO. Geneva: World Health Organization.

[5]. Mezzich JE, Kirisici L, Salloum IM (2014): ICPCM Project on the Systematic Conceptualization and Measurement of Person- 
and People-centered Care. Technical Report, International College of Person Centered Medicine, New York, 2014.

[6]. Appleyard J (2013): Introduction to Ethical Standards for Person-centered Health Research. International Journal of Person Centered Medicine 3: 258-262.

[7]. Bouësseau M-C (2013): Strengthening Research Ethics Review Systems. International Journal of Person Centered Medicine 3: 263-265.

[8]. International College of Person Centered Medicine (2012): Geneva Declaration on Person Centered Care for Chronic Diseases. International Journal of Person Centered Medicine 2: 153-154.

[9]. International College of Person Centered Medicine (2013). Geneva Declaration on Person Centered Health Research. International Journal of Person Centered Medicine, 3:106-107.

[10]. Salvador L, Cloninger CR, Thornicroft A, Mezzich JE et al (2013). Geneva Declaration on Person Centered Health Research. International Journal of Person Centered Medicine, 3: 109-113.

[11]. International College of Person Centered Medicine (2013).

Zagreb Declaration on Person-centered Health Professional Education. International Journal of Person Centered Medicine, 3: 6-7.

[12]. Appleyard J, Ghebrehiwet T, Mezzich JE (2013). Development and implications of the Zagreb Declaration on Person-centered Health Professional Education. International Journal of Person Centered Medicine, 3: 8-13.

[13]. International College of Person Centered Medicine: 2014 Geneva Declaration on Person- and People-centered Integrated Health Care for All. International Journal of Person Centered Medicine 4: 66-68.

[14]. Cloninger CR, Salvador-Carulla L, Kirmayer L J, Schwartz MA, Appleyard J, Goodwin N, Groves J, Hermans MHM, Mezzich JE, van Staden CW, and Salman Rawaf: A Time for Action on Health Inequities: Foundations of the 2014 Geneva Declaration on Person- and People-centered Integrated Health Care for All. International Journal of Person Centered Medicine. 4: 69-89.

[15]. Braaf S, Rixon S, Williams A, Liew D, and Manias E: Pharmacist-Patient Medication Communication During Admission and Discharge in Specialty Hospital Settings: Implications for Person Centered Healthcare. International Journal of Person Centered Medicine 4: 90-105.

[16]. Gunnarsson A-K, Larsson J, and Gunningberg L. Hipfracture Patients' Experience of Involvement in their Care: A qualitative study. International Journal of Person Centered Medicine 4: 106-114.

[17]. Nes AAG, Brembo EA, van Dulmen S, Kristjánsdóttir OB, Wicksell R, and Eide H: Examining Fidelity of Web-based Acceptance and Commitment Interventions for Women with Chronic Widespread Pain. International Journal of Person Centered Medicine 4: 115-125.

[18]. Basara L, Jalušić Glunčić T, Maletić O, Pelicarić D, Popović Grle S , Samaržija M, and Jakopović M: PersonCentered Approach In Pulmonary Rehabilitation. International Journal of Person Centered Medicine 4: 126-130.

[19]. Walsh B: A Neo-pragmatist View of Evidence-Based Medicine. International Journal of Person Centered Medicine 4:131-138.

[20]. Walsh B (2014): A view of Evidence-based Medicine from Karl Popper. International Journal of Person Centered Medicine 4: 35-43. 